\title{
No effect of mate novelty on sexual motivation in the freshwater
} snail Biomphalaria glabrata

\author{
Ines K Häderer ${ }^{\dagger}$, Johanna Werminghausen ${ }^{\dagger}$, Nico K Michiels, \\ Nadine Timmermeyer and Nils Anthes* ${ }^{*}$
}

\begin{abstract}
Address: Animal Evolutionary Ecology, Institute for Evolution and Ecology, Eberhard Karls-Universität Tübingen, Auf der Morgenstelle 28, 72076 Tübingen, Germany

Email: Ines K Häderer - ines.haederer@student.uni-tuebingen.de; Johanna Werminghausen - johannawerminghausen@t-online.de; Nico K Michiels - nico.michiels@uni-tuebingen.de; Nadine Timmermeyer - nadine.timmermeyer@uni-tuebingen.de; Nils Anthes* - nils.anthes@uni-tuebingen.de

* Corresponding author †Equal contributors
\end{abstract}

Published: 12 October 2009

Frontiers in Zoology 2009, 6:23 doi:10.1186/1742-9994-6-23
Received: 16 July 2009

Accepted: 12 October 2009

This article is available from: http://www.frontiersinzoology.com/content/6/1/23

(C) 2009 Häderer et al; licensee BioMed Central Ltd.

This is an Open Access article distributed under the terms of the Creative Commons Attribution License (http://creativecommons.org/licenses/by/2.0), which permits unrestricted use, distribution, and reproduction in any medium, provided the original work is properly cited.

\begin{abstract}
Background: When mating effort (e.g. via ejaculates) is high, males are expected to strategically allocate their resources depending on the expected fitness gains from a given mating opportunity. One mechanism to achieve strategic mating is the Coolidge effect, where male sexual motivation declines across repeated encounters with a familiar partner, but resuscitates when encountering a novel female. Experimental tests of male mate choice via mechanisms such as the Coolidge effect, however, remain scarce. Moreover, it is untested to date whether the Coolidge effect occurs in a sex-specific manner in simultaneous hermaphrodites, where the motivation to mate with a familiar partner may vary with previous mating activity in the male or female role.

Results: We exposed focal hermaphroditic freshwater snails, Biomphalaria glabrata, repeatedly to either a familiar or a novel partner. None of our proxies of sexual motivation (remating likelihood, mating delay, copulation duration) varied between the novel and familiar partner treatments. Moreover, the mating role taken during the first copulation did not affect the subsequent choice of mating roles in the familiar partner treatment as would be expected if focals preferred to avoid mating twice in the same role with a familiar partner. This indicates the absence of sex-specific effects of partner novelty.

Conclusion: Our data indicate that mate novelty does affect neither overall sexual motivation nor the choice of mating roles in B. glabrata. Hence, male mate choice via a Coolidge effect appears inexistent in this invertebrate hermaphrodite. We discuss the possible roles of insufficient fitness gains for discriminatory behaviour in populations with frequent mate encounters as well as poor mate discrimination capacities. Our findings lend also no support to the novel prediction that sexual motivation in simultaneous hermaphrodites varies with the mating roles taken during previous copulations, calling for empirical investigation in further hermaphrodite systems.
\end{abstract}




\section{Background}

While the metabolic costs of producing a single sperm cell are almost negligible, the total paternal investment in sperm and seminal fluid that is required to sire a single offspring may often match the maternal per egg investment [1-4]. Males thus benefit from carefully choosing their mating partners and prudently adjusting mating effort (e.g., ejaculate size) to the expected gain in reproductive success. Even though mechanisms of male mate choice are subject to rising attention (reviewed in [5-7]), empirical assessments remain scarce compared to the large body of literature devoted to female mate preferences. Emerging evidence now indicates that male mating propensity and sperm allocation to individual partners can indeed vary in response to female fecundity or the risk of sperm competition in fruit flies [3,8], crickets [9-11], butterflies [12], or birds [13].

An additional way in which males could strategically distribute sperm is by preferring copulations with novel mates over copulations with familiar partners. This should be beneficial under three conditions [6]. First, frequent mating exhausts male sperm stores such that males that multiply inseminate the same female risk sperm depletion upon their next encounter with a novel female. Second, repeated inseminations of the same female generate diminishing fitness returns for sperm investment due to increased competition among this male's sperm. The latter excludes cases where high 'sperm doses' within the female reproductive tract are necessary to achieve fertilisation success [14]. Third, the likelihood of encountering a novel partner is sufficiently high. Then, males should deliver smaller ejaculates in consecutive inseminations of a given female to conserve sperm reserves for future matings with novel partners that offer higher fecundity potential [6], and thus seek opportunities to secure a novel mate.

A proximate mechanism to mediate such a strategy is a decline in male sexual motivation when encountering familiar partners [15]. This process, often referred to as the Coolidge effect [16], has originally been defined when sexual satiation with a familiar female is followed by a restoration of male mating behaviour after exposure to a novel female [17]. Subsequent studies specified further proxies for 'satiation' or a 'restoration of mating behaviour' $[6,18]$. Accordingly, the Coolidge effect could manifest via (i) mate rejection, (ii) increased reluctance to mate, or (iii) the donation of smaller ejaculates when encountering a familiar partner.

The Coolidge effect requires an ability to differentiate between familiar and novel sexual partners. Since such cognitive capacities may primarily be expected in vertebrates, it comes as no surprise that experimental tests have some tradition primarily in rodents and livestock [17,1924]. Only few studies to date explicitly assessed the Coolidge effect in invertebrates: In the hermaphroditic freshwater snail, Lymnaea stagnalis, Koene \& Ter Maat [25] found a higher incidence of remating in focal individuals that were confronted with a novel rather than with a familiar partner. Likewise, Steiger et al. [26] showed that sexual motivation in the burying beetle, Nicrophorus vespilloides, is restored if an unfamiliar female is introduced to a male that had been exposed four times to a familiar female. In the cricket, Gryllus bimaculatus, Bateman [27] showed that the Coolidge effect is by no means restricted to males, but can also be expressed by females. This is beneficial whenever polyandrous matings enhance female fitness relative to multiple matings with the same male $[18,28]$. A similar discriminatory behaviour is shown by female decorated crickets, Gryllodes sigillatus [29], where a follow-up study showed that mate choice via a Coolidge effect is only expressed in females and not in males [30]. Some further studies, while not explicitly addressing the Coolidge effect, documented patterns that match a scenario of restored male (or female) sexual motivation when encountering unfamiliar partners [31-35]. Taken together, these studies suggest that the Coolidge effect may be more prevalent among invertebrates than previously thought, but generalisations require studies from a greater diversity of taxa.

Simultaneous hermaphrodites can express the Coolidge effect in an intriguing additional way. Here, sexual motivation may vary with the mating roles adopted during previous copulations. Imagine a focal individual that encounters a familiar partner with which it previously mated in the female role. The focal should now be less motivated to take the female role a second time, but highly motivated to adopt the male role. The reverse pattern of sexual motivation is expected in the partner, predicting that mating roles are alternated between the first and second copulation. In contrast, focals encountering a novel partner should display high motivation to exhibit both sex functions (with the same being true for their partner), predicting random choice of mating roles. Analysing the choice of mating roles as a function of partner familiarity thus represents a novel approach to complement previous explanations for the variable patterns of sex role alternation displayed by simultaneous hermaphrodites (e.g. [36-40]).

In the current study we seek hints for a Coolidge effect in the tropical pulmonate freshwater snail Biomphalaria glabrata. This preferentially outcrossing simultaneous hermaphrodite inhabits small streams and ponds in large populations [41] where familiar partners could be rejected at low costs. The typically unilateral copulations [42] are initiated when a male actor mounts the shell of a 
prospective mate. The male actor then moves towards the frontal left edge of the partner's shell, where it probes the female gonopore with its penis to subsequently achieve penis intromission. Following a typically 5-87 $\mathrm{min}$ penis intromission with usually successful sperm transfer [43], the male actor retracts to terminate copulation. Mating roles are subsequently exchanged in about $45 \%$ of all copulations, with the male actor now taking the female role, and vice versa. In non-manipulated laboratory observations, individual B. glabrata did not exhibit any preference to copulate in the male or female mating role, nor were there indications for non-random alternation of mating roles [44] as would be expected in systems with conditional reciprocity [45-47]. Nonetheless, given that excess sperm are often digested rather than used for fertilisation $[48,49]$, individuals would clearly benefit from retaining costly sperm and seminal fluid for novel rather than familiar partners.

To detect changes in sexual motivation as predicted by the Coolidge effect, we first measured remating likelihood, the delay until penis intromission, and intromission duration in focal snails consecutively confronted with either novel or familiar partners (see Fig. 1 and Methods section). Second, we related male sexual motivation to the mating roles adopted during previous copulations. Hence, for the first time, we investigated the interaction between the choice of mating roles and the Coolidge effect in a simultaneous hermaphrodite.

\section{Results}

\section{Mate novelty and sexual motivation}

The predicted decrease in sexual motivation in 'familiar partner' focals relative to 'novel partner' focals should manifest in a significant time* treatment interaction in our repeated measures analysis (see Methods for details). Contrary to this expectation, interaction terms were highly insignificant for all our measurements of mating delay and copulation duration (all $P>0.29$; Table 1 ; two examples displayed in Figs. 2 and 3). Three measurements (delay until intromission start, delay until intromission end, and duration from first contact to intromission) significantly decreased over time in both treatments, indicating that the overall mating propensity increased over a day.

\section{Mate novelty and mating roles}

We further hypothesised that partner novelty should affect the propensity to change mating roles, such that focals meeting a familiar partner in their second mating should preferentially assume the female mating role, whereas focals meeting a novel partner should assume their mating role at random. In contrast to this prediction, we found random choice of mating roles in both treatment groups ('familiar partner': Likelihood Ratio $\chi^{2}=$
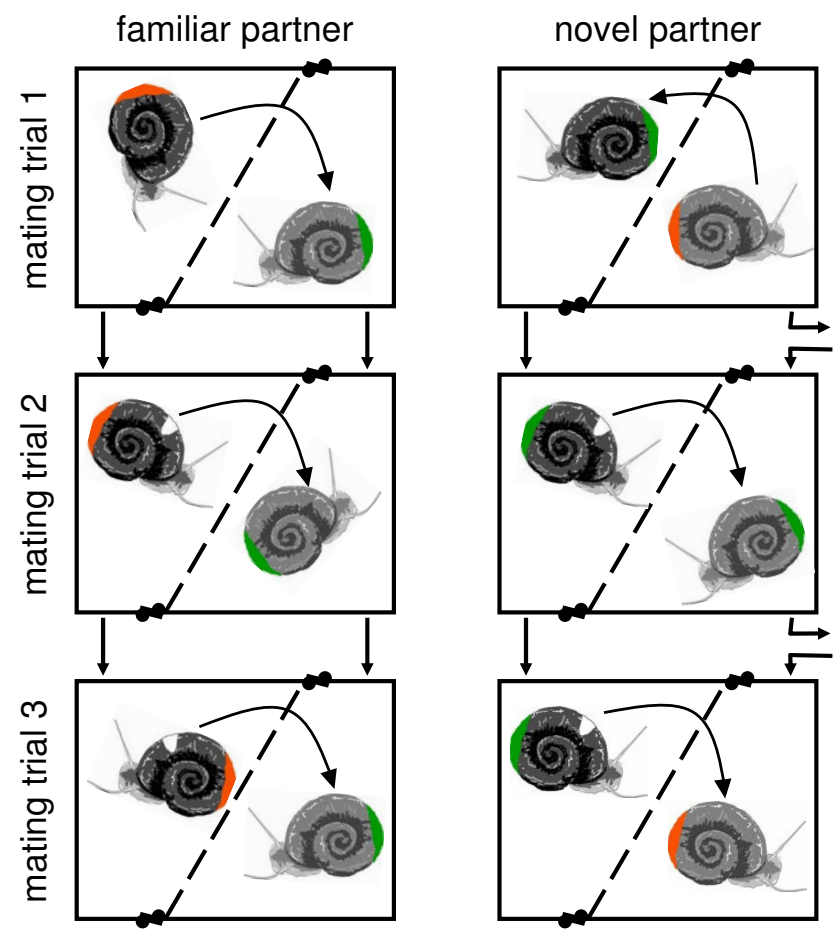

\section{Figure I}

Experimental setup illustrating the two treatments and three successive mating trials. Green and orange labels served to distinguish snails during the first mating trial and were applied randomly within pairs. The male actor from the first mating trial was defined 'focal' and marked with an additional white dot. Curved arrows indicate which of the two snails was transferred to the partner's compartment (random during first mating, the focal in both other matings). The small arrows between observation boxes show whether pairs stayed together in the same constellation ('familiar partner') or whether the focal individual obtained a new partner for each mating ('novel partner').

1.707; $\mathrm{df}=1 ; P=0.19$; 'novel partner': Likelihood ratio $\chi^{2}$ $=1.263, \mathrm{df}=1 ; P=0.26$ ). Consequently, the two treatment groups did not differ in the proportion of focal snails that changed their mating role from first to second mating (Likelihood Ratio $\chi^{2}=0.067 ; \mathrm{df}=1 ; P=0.79$; Fig. 4) or from second to third mating (Likelihood Ratio $\chi^{2}=$ $0.016 ; \mathrm{df}=1 ; P=0.89)$.

\section{Discussion}

Under our first hypothesis, we assessed the key prediction of the Coolidge effect that focal snails repeatedly exposed to a familiar partner should show a decline in sexual motivation relative to focals exposed to novel partners. Yet, none of our proxies of sexual motivation revealed any divergence in behavioural traits between treatments across the three mating trials. This strongly indicates that, at least within our experimental paradigm, B. glabrata 


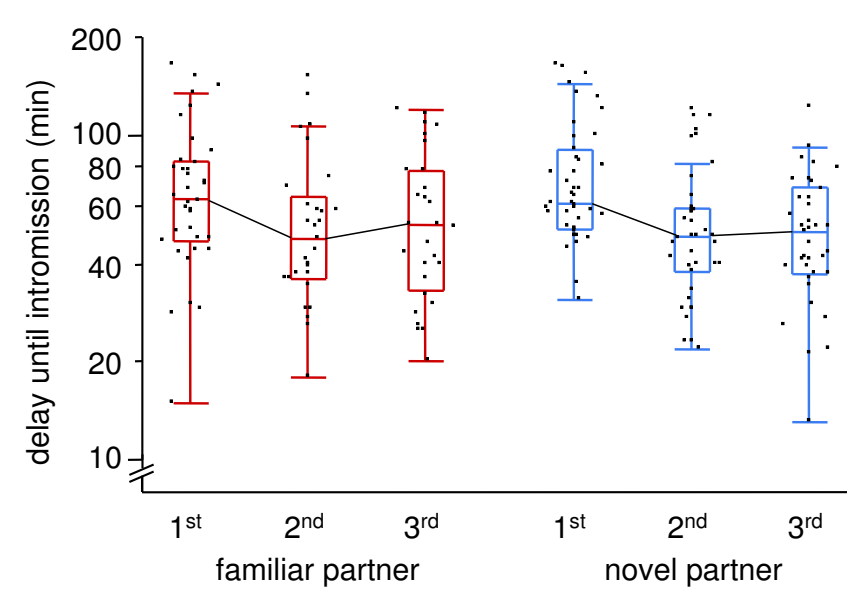

Figure 2

Delay until penis intromission across the three consecutive mating trials within novel partner and familiar partner treatments. The Box-plot (note logarithmic scale on y-axis) also shows original data points (jittered) and connects the medians per trial with a line to indicate that the analysis was based on repeated measures per individual. For statistics see Table I.

does not perform mate discrimination based on partner novelty.

As an ultimate reason, the costs of male matings in B. glabrata may not be sufficiently high to select for strategic mate discrimination und prudent mating effort, which may contrast with the pond snail, Lymnaea stagnalis, for which an effect of partner familiarity on male mating motivation has recently been demonstrated [25]. Circumstantial support for this hypothesis comes from the observation that mating rates in $B$. glabrata [44] are substantially higher than those found in L. stagnalis, where the restoration of seminal fluids may take several days [37]. Hence, male sperm depletion appears to be much less likely in B. glabrata, reducing the benefits of prudent mate discrimination.

As a second explanation, the fitness gains from inseminating novel mates may not sufficiently exceed those from repeatedly inseminating the same female. B. glabrata snails lay egg masses at a rather high rate (about 1 per day, [50]) such that repeated inseminations of the same female may indeed provide fertilisation chances similar to those of insemination a novel female. On the other hand, however, previous studies show that single ejaculates are sufficient to fertilise consecutive egg masses for several weeks in this species [51,52], rather suggesting low fitness returns for 'topping up' sperm stores in short succession [14]. Measurements revealing the net effect of these opposing effects of multiple mating are necessary to eval- uate this hypothesis for an absence of a Coolidge effect in B. glabrata.

A third explanation refers to the spatial population composition. A recent study in wild guppies found mate discrimination for partner novelty only in confined populations where individuals could familiarise with each other, whereas discriminatory behaviour did not occur in open river populations [53]. Our study population was long maintained at high population densities, where random mate encounters usually occur with novel partners, perhaps making mate discrimination obsolete. In the natural habitats of B. glabrata, founder events and seasonal variation in water flux may occasionally confine small groups to isolated water pools [22]. It is conceivable that such groups may temporarily display discriminatory behaviour conforming to a Coolidge effect, providing a promising avenue for further research.

The absence of a Coolidge effect in B. glabrata could also have a proximate basis, where snails may be incapable of using cues that discriminate novel from familiar partners. First, self-referent tags as documented for decorated crickets [29] could be left within the mucus that snails leave on a partner's shell during copulation [25]. B. glabrata mucus contains species-specific signals that allow identifying conspecifics [54]. However, even if these cues were informative for individual discrimination, the causative mucus components decay within 10 to $30 \mathrm{~min}$ [54,55] and would thus only work as a short term self-referent cue. Given a delay between copulations of $1 h$ and more and the long time over which received allosperm can be stored to produce fully fertile egg masses (3 weeks at least, $[52,56])$, this mechanism appears insufficient to allow partner discrimination in B. glabrata. Second, snails may individually recognise previous partners as recently shown for a burying beetle [26]. This would allow discrimination for much longer intervals, but requires snails to process and memorize this more complex information. B. glabrata is known to perform sophisticated partner discrimination based on current and potential parasite infections status [57]. Moreover, other pulmonates such as $L$. stagnalis express conditioned behaviour for up to several weeks, indicating long-term memory [58,59]. Yet, a capability of $B$. glabrata to remember individual chemical cues for several hours at least has not been shown to date and may be questionable in the light of our findings.

Part of the discrepancy between our study and the findings in L. stagnalis could also be due to differences in the experimental designs. While Koene \& Ter Maat [25] initiated their experiment with snails isolated for two weeks, we kept isolation times short to closely mimic the natural conditions under which a biologically relevant Coolidge effect would have to be detectable. Hence, even though 
Table I: Effects of treatment ('novel' vs. 'familiar partner'), time (three successive trials), and their interaction on various measures of mating delay and copulation duration.

\begin{tabular}{|c|c|c|c|c|c|}
\hline Source & df & SS & $\mathbf{F}$ & $P$ & $R^{2}$ (adj.) \\
\hline \multicolumn{6}{|l|}{ Delay until Ist contact } \\
\hline Model & 69 & 37.743 & 0.919 & 0.6459 & -0.029 \\
\hline Treatment & 1 & 1.672 & 3.170 & 0.0797 & \\
\hline Time & 2 & 1.994 & 1.676 & 0.1912 & \\
\hline Time*treatment & 2 & 0.495 & 0.416 & 0.6605 & \\
\hline Individual(treatment) & 64 & 33.757 & 0.887 & 0.7009 & \\
\hline Error & 128 & 76.160 & & & \\
\hline \multicolumn{6}{|l|}{ Delay until Ist penis eversion } \\
\hline Model & 69 & 31.732 & 1.193 & 0.1946 & 0.063 \\
\hline Treatment & 1 & 0.340 & 0.743 & 0.3919 & \\
\hline Time & 2 & 1.988 & 2.579 & 0.0798 & \\
\hline Time*treatment & 2 & 0.358 & 0.464 & 0.6299 & \\
\hline Individual(treatment) & 64 & 29.251 & 1.186 & 0.2075 & \\
\hline Error & 128 & 49.345 & & & \\
\hline \multicolumn{6}{|l|}{ Delay until intromission start } \\
\hline Model & 69 & 18.425 & 1.178 & 0.2114 & 0.059 \\
\hline Treatment & I & 0.029 & 0.131 & 0.7186 & \\
\hline Time & 2 & 3.286 & 7.250 & 0.0010 & \\
\hline Time*treatment & 2 & 0.503 & 1.110 & 0.3328 & \\
\hline Individual(treatment) & 64 & 14.131 & 0.974 & 0.5382 & \\
\hline Error & 128 & 29.009 & & & \\
\hline \multicolumn{6}{|l|}{ Delay until intromission end } \\
\hline Model & 69 & 12.624 & 1.292 & 0.1066 & 0.093 \\
\hline Treatment & 1 & 0.017 & 0.107 & 0.7451 & \\
\hline Time & 2 & 1.940 & 6.848 & 0.0015 & \\
\hline Time*treatment & 2 & 0.391 & 1.382 & 0.2548 & \\
\hline Individual(treatment) & 64 & 9.956 & 1.099 & 0.3231 & \\
\hline Error & 130 & 18.127 & & & \\
\hline \multicolumn{6}{|l|}{ Duration from Ist contact to penis eversion } \\
\hline Model & 69 & 48.874 & 0.890 & 0.6999 & -0.040 \\
\hline Treatment & 1 & 0.143 & 0.192 & 0.6629 & \\
\hline Time & 2 & 0.838 & 0.527 & 0.5918 & \\
\hline Time*treatment & 2 & 0.116 & 0.073 & 0.9298 & \\
\hline Individual(treatment) & 64 & 47.790 & 0.939 & 0.6053 & \\
\hline Error & 127 & 101.047 & & & \\
\hline \multicolumn{6}{|l|}{ Duration from Ist contact to intromission } \\
\hline Model & 69 & 28.061 & 1.368 & 0.0641 & 0.114 \\
\hline Treatment & 1 & 0.001 & 0.002 & 0.9669 & \\
\hline Time & 2 & 6.946 & 11.682 & $<0.0001$ & \\
\hline Time*treatment & 2 & 0.621 & 1.044 & 0.3549 & \\
\hline Individual(treatment) & 64 & 19.672 & 1.034 & 0.4295 & \\
\hline Error & 128 & 38.055 & & & \\
\hline \multicolumn{6}{|l|}{ Intromission duration } \\
\hline Model & 69 & 13.664 & 1.187 & 0.2017 & 0.061 \\
\hline Treatment & 1 & 0.002 & 0.008 & 0.9273 & \\
\hline Time & 2 & 0.104 & 0.312 & 0.7326 & \\
\hline Time*treatment & 2 & 0.114 & 0.340 & 0.7121 & \\
\hline Individual(treatment) & 77 & 13.473 & $1.26 \mid$ & 0.1342 & \\
\hline Error & 128 & 21.361 & & & \\
\hline
\end{tabular}

The factor individual (nested within treatment) represents the within subject effect of the repeated measures ANOVA.

small motivational effects may have gone unseen in our study, these are unlikely to affect natural behaviour. Moreover, Koene \& Ter Maat [25] found the Coolidge effect most pronounced in snails maintained in their own 'dirty' water. We placed snails into new observation chambers for each mating trial, but allowed them to sequester chemical compounds and mucus for $1 h$ prior to mating trials. This ensured that chemical cues for partner discrimination (e.g. waterborne signals or mucus trails) could still be delivered, but simultaneously avoided that treatments dif- 


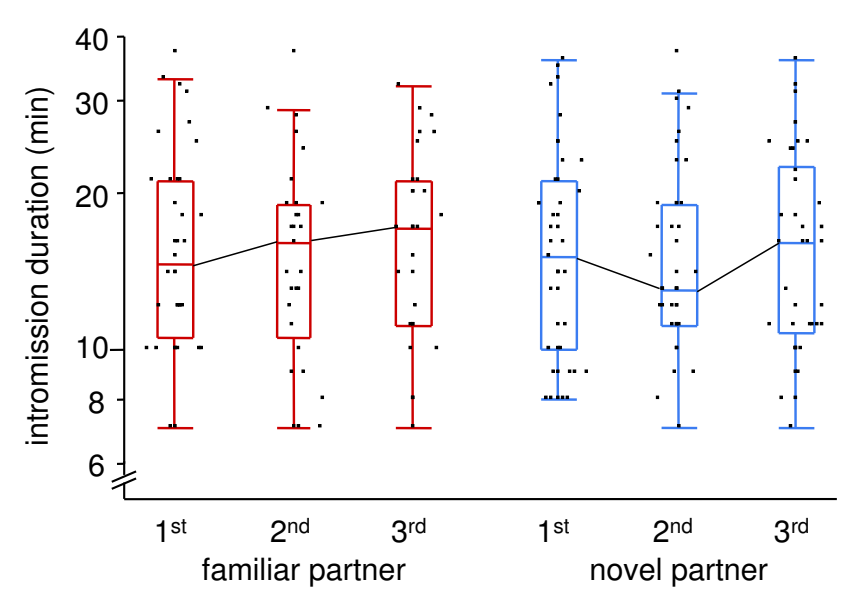

Figure 3

Penis intromission durations across the three consecutive mating trials within novel and familiar partner treatments. See Fig. 2 and Table I for display and statistics, respectively.

fered in a second factor: if focal snails are kept in their original aquaria, both snails in 'familiar partner' replicates always experience a known environment, whereas the changing partners in 'novel partner' replicates are confronted with a new environment in each mating trial.

Our second hypothesis predicted that focal snails, having all mated in the male role in their first mating, should preferentially assume the female role when encountering the same partner a second time. In contrast, mating roles should be taken at random when the second mate is novel. Contrary to this prediction, the observed changes

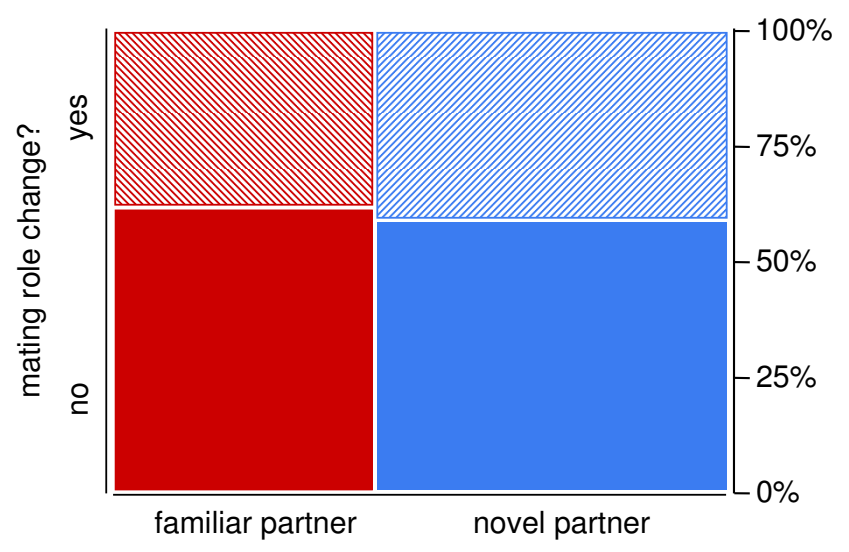

\section{Figure 4}

Mating role changes between a focal snails' first and second mating. The mosaic plot shows the proportion of focal individuals switching roles split between 'familiar partner' $(n=29)$ and 'novel partner' $(n=39)$ treatment. in mating roles between first and second mating trial did not deviate from the random 1:1 distribution in either group. Moreover, when testing the two experimental groups directly against each other, we found no difference in the frequency of mating role change to the second or to the third mating. These findings indicate that, independent of mate novelty, previous mating history does not affect the subsequent choice of mating roles in B. glabrata. These conclusions complement an earlier observational study that documented random alternation of mating roles and no preference for one particular mating role in snails that were kept in larger groups [44]. It is known that mating roles in $B$. glabrata copulations are determined very early during courtship where the active snail will later take the male role [42]. Yet, to date, the ultimate and proximate factors that determine these activity levels remain obscure.

\section{Conclusion}

Our study shows that effects of mate novelty on sexual motivation may be less prevalent than previously thought. Candidate reasons for the absence of a Coolidge effect in B. glabrata include a low benefit to cost ratio of discriminatory behaviour as well as the absence of the required proximate mechanisms to distinguish novel from familiar partners. Disentangling these alternatives will be an important goal for further research. We further find no evidence for the novel hypothesis that sex-specific familiarity affects the choice of mating roles in this simultaneous hermaphrodite. Future work should address this idea in further systems that represent a broader range of ecological and social contexts to elucidate the generality of our findings.

\section{Methods \\ Experimental groups and sample sizes}

Our experiment contained two treatments. Treatment 1 ('familiar partner') served as our baseline control. Here, focal individuals were repeatedly exposed to a familiar partner during three successive mating trials. In treatment 2 ('novel partner') snails were confronted with a novel partner in each of the three trials (Fig. 1). With a Coolidge effect present, we expected 'novel partner' focals to show lower rejection rates, shorter mating delays and/or longer copulations than 'familiar partner' focals.

In total we initiated 40 replicates (80 snails) in the 'familiar partner' treatment and 56 replicates (112 snails) in the 'novel partner' treatment. This difference in initial sample size was necessary because, in order to exclusively test for the effect of mate novelty, we had to standardise the history of previous mating roles in the 'novel partner' treatment. In the 'familiar partner' treatment, previous mating roles of both snails per replicate are automatically complementary across all three mating trials. In the 'novel 
partner' treatment, we therefore had to similarly assure that focal snails obtained a partner with a complementary mating history. For example, a focal snail that had mated in the male role in both its first and second mating must for its third mating - be exposed to a 'novel partner' that had previously mated twice in the female role. The initially larger number of replicates in this treatment group buffered the expected loss of focal snails for which we could not provide complementary partners in all three mating trials.

\section{Experimental procedure}

Our experimental snails originated from a large laboratory stock population $(\mathrm{N} \sim 500)$ that has been kept at constant water temperature $\left(26^{\circ} \mathrm{C}\right)$ and a $12 \mathrm{~h}: 12 \mathrm{~h}$ light:dark cycle for several dozen generations. Prior to the experiment, 150 snails each were placed in two $60 \mathrm{l}$ freshwater tanks. This assured that we were measuring the relevance of the Coolidge effect under high density conditions as often encountered in the field, and excluded the possibly confounding effects of an elevated mating propensity when encountering virgin partners [60].

As it was impossible to simultaneously observe all 96 replicate pairs, we spread our experiment across four consecutive observation days (experimental runs). During each run we observed 10 'familiar partner' and 14 'novel partner' replicates in parallel. In order to simulate the high rate at which $B$. glabrata typically meet (at least 4 matings in $12 h,[44])$, all three mating trials per replicate were performed within a $12 \mathrm{~h}$ period. The following describes the experimental procedure for a single experimental run (Fig. 1 ), which was identically repeated for the remaining three runs.

$60 h$ prior to observation, we randomly selected 48 mature snails and placed them in groups of six in $1.5 \mathrm{l} \mathrm{PE}-$ boxes. The six snails per box were isolated by perforated plastic walls but shared the same water to perceive the presence of other snails [61]. $42 \mathrm{~h}$ prior to observation, snails were fed with organic lettuce ad libitum. Since body size may affect mating behaviour, snails were allocated to treatment groups randomly with respect to body size, but we size-matched partners within allocated pairs as closely as possible. Mean shell diameter of all experimental snails was $1.63 \mathrm{~cm} \pm 0.26 \mathrm{~cm} \mathrm{SD}$ (range $1.0 \mathrm{~cm}$ to $2.1 \mathrm{~cm}$ ). Diameters did not vary between our experimental groups both overall and within each observation day (all ANOVA $P>0.25)$. The two snails per pair were individually marked with orange and green paint markers to enable individual recognition. In a related freshwater snail, Physa acuta, these paints do not affect individual condition [62] and accordingly showed no effect on mating role choice in our first mating trial (Likelihood Ratio $\chi^{2}=0.114 ; \mathrm{df}=1$; $P=0.74)$.
The observation day (consisting of the three consecutive mating trials) started with the light phase. The two snails per allocated pair were placed in a transparent, rectangular plastic box with $190 \mathrm{ml}$ fresh water at $26^{\circ} \mathrm{C}$. Individuals remained separated for $1 h$ by a perforated transparent partition to allow mucus secretion and visual as well as chemical communication but prevent direct contact. Thereafter, both individuals were briefly lifted out of the container and placed randomly together in one of the two compartments. We now recorded the behaviour of all snails for $3 h(\mathrm{~N}=24$ pairs). Following a successful mating, pairs were immediately separated and returned to their former compartment for the remaining observation period. Pairs were not allowed to mate reciprocally and were separated if necessary. We only counted penis intromissions exceeding $5 \mathrm{~min}$ as successful copulations [42]. Snails that were not mating or probing were separated after $2 h$ and $50 \mathrm{~min}$. Pairs that did not copulate during the first mating trial were excluded from the experiment.

After this first mating, the individual performing the male role was determined 'focal' for all consecutive trials and subsequent analyses. Focals were now additionally marked with a white dot (Fig. 1).

Handling procedures for the second and third mating trials per run were almost identical (Fig. 1). Snails were first transferred into new compartmented boxes with fresh water. 'Familiar partner' focals were paired to their previous mating partner. 'Novel partner' focals obtained an unfamiliar partner with a complementary mating history (as outlined above). These changing partners randomly rotated between pairs of the second treatment. Following the initial $1 \mathrm{~h}$ of separation (again allowing mucus secretion and chemical communication), both snails were lifted again, and this time always placed in the compartment of the novel or familiar partner.

\section{Measurements}

As proxies of sexual motivation, we recorded in each trial (i) whether mating took place or not, (ii) the mating roles taken, (iii) copulation latency, and (iv) copulation duration. Copulation latency was approximated by multiple alternative measures: delay until first contact; delay until first penis eversion; delay until intromission start and end; time lag between first body contact and penis eversion; time lag between first body contact and start and end of intromission. Copulation duration may not necessarily reflect the amount of semen transferred, but for the purpose of our study we consider shorter copulations a useful proxy of declining sexual motivation. Copulation duration was approximated by the time interval between penis intromission and retraction. Successful penis intromission into the partner's gonopore was reliably indicated 
with the penis reaching under the partner's frontal left shell opening without further movements (unpubl. data).

\section{Analyses}

We used repeated measures ANOVAs to assess the differential effects of treatment on all continuous (time) measurements across the three consecutive mating trials (i.e., the three repeated measures per focal). In these analyses, a Coolidge effect would become visible in a significant interaction between the fixed factors treatment and mating trial. For example, 'familiar partner' focal snails should show a steeper increase in mating delay than 'novel partner' focals that maintained sexual motivation. Model parameters were derived from a two-way nested ANOVA, with treatment and mating trial as fixed factors and individual ID as a factor nested within treatment [63]. Original data varied neither between observers nor between experimental runs, such that both these factors where omitted from the final reported analyses. After log-transforming all continuous variables, none of these violated the RM-ANOVA assumption of sphericity [63]. We therefore only report the uncorrected results. After excluding dead snails and their partners, non-mating pairs in the first mating trial, or 'novel partner' focals for which we could not find a mate with complementary history, all RM ANOVAs are based on $n=28$ focal snails in the 'familiar partner' treatment and $n=38$ focal snails in the 'novel partner' treatment.

Changes in the mating roles of focal individuals were analysed using a two dimensional frequency test. We first compared the two treatments between first and second mating trial ('familiar partner' treatment $n=29$; 'novel partner' treatment $n=39$ ) and between second and third mating trial ('familiar partner' treatment $n=28$; 'novel partner' treatment $n=38$ ). Second, we tested separately for each treatment whether the proportion of focals mating in the male or female role deviated from the random $1: 1$ expectation.

All data analyses were performed using JMP 7.0.2 statistical package (SAS Inc.).

\section{Competing interests}

The authors declare that they have no competing interests.

\section{Authors' contributions}

IH and JW carried out the study, participated in its design and analysis, and drafted the manuscript. NM and NT contributed to the study design and manuscript preparation. NA coordinated study design, statistical analysis, and manuscript preparation. All authors read and approved the final manuscript.

\section{Acknowledgements}

We thank Heinz-R. Köhler for providing access to the climate chamber, Wolfgang Hoffmann for supplying snails, Tobias Gerlach, Christian Gümpel, Dubravka Miling, Andreas Ölkrug, and Gregor Schulte for assistance with aquarium setups and maintenance, and Joris $M$. Koene, Andreas Lengerer, Manfred Milinski, Dennis Sprenger, and one anonymous referee for constructive comments on earlier versions of the manuscript. The establishment of the aquarium facilities was funded by a young researcher grant (Förderung für Nachwuchswissenschaftler) of the University of Tübingen to N.A.

\section{References}

I. Dewsbury DA: Ejaculate cost and male choice. Am Nat 1982 , I 19:601-610.

2. Nakatsuru K, Kramer DL: Is sperm cheap? Limited male fertility and female choice in the lemon tetra (Pisces, Characidae). Science 1982, 2 1 6:753-755.

3. Gage MJG: Risk of sperm competition directly affects ejaculate size in the Mediterranean fruit fly. Anim Behav 1991, 42: $1036-1037$.

4. Olsson M, Shine R, Madsen T, Gullberg A, Tegelström H: Sperm selection by females. Nature 1996, 383:585.

5. Bonduriansky R: The evolution of male mate choice in insects: a synthesis of ideas and evidence. Biol Rev 200I, 76:305-339.

6. Wedell N, Gage MJG, Parker GA: Sperm competition, male prudence and sperm-limited females. Trends Ecol Evol 2002, I 7:313-320.

7. Clutton-Brock T: Sexual selection in females. Anim Behav 2009, 77:3-II.

8. Pitnick S, Markow TA: Male gametic strategies: sperm size, testes size, and the allocation of ejaculate among successive mates by the sperm-limited fly Drosophila pachea and its relatives. Am Nat 1994:785-819.

9. Gage AR, Barnard CJ: Male crickets increase sperm number in relation to competition and female size. Behav Ecol Sociobiol 1996, 38:349-353.

10. Simmons LW, Craig M, Llorens T, Schinzig M, Hosken D: Bushcricket spermatophores vary in accord with sperm competition and parental investment theory. Proc $R$ Soc Lond $B$ 1993:183-186.

II. Thomas ML, Simmons LW: Male-derived cuticular hydrocarbons signal sperm competition intensity and affect ejaculate expenditure in crickets. Proc $R$ Soc Lond B 2009, 276:383-388.

12. Cook PA, Wedell N: Ejaculate dynamics in butterflies: a strategy for maximizing fertilization success? Proc $R$ Soc Lond $B$ 1996:1047-1051.

13. Pizzari T, Cornwallis CK, Birkhead TR, Løvlie H, Jakobsson S: Sophisticated sperm allocation in male fowl. Nature 2003, 426:70-74.

14. Parker GA: Sperm competition and the evolution of ejaculates: towards a theory base. In Sperm Competition and Sexual Selection Edited by: Birkhead TR, Møller AP. London: Academic Press; 1998:3-54.

15. Beach FA, Jordan L: Sexual exhaustion and recovery in the male rat. Quat J Exp Psychol 1956, 8: I21-133.

16. Wilson JR, Kuehn RE, Beach FA: Modification in the sexual behavior of male rats produced by changing the stimulus female. J Comp Physiol Psychol 1963, 56:636-644.

17. Dewsbury DA: Effects of novelty on copulatory behavior: The Coolidge effect and related phenomena. Psychol Bull I98I, 89:464-482.

18. Pizzari T: Sperm allocation, the Coolidge effect and female polyandry. Trends Ecol Evol 2002, I 7:456-456.

19. Brown RE: Sexual arousal, the Coolidge effect and dominance in the rat (Rattus norvegicus). Anim Behav 1974, 22:634-637.

20. Lisk RD, Baron G: Female regulation of mating location and acceptance of new mating partners following mating to sexual satiety: the Coolidge effect demonstrated in the female golden hamster. Behav Neur Biol 1982, 36:416.

21. Lester GL, Gorzalka BB: Effect of novel and familiar mating partners on the duration of sexual receptivity in the female hamster. Behav Neur Biol 1988, 49:398. 
22. Wethington AR, Zavodna M, Smith MK, Oliveira G, Lewis F, Minchella DJ: Population genetic structure of Biomphalaria glabrata in a schistosomiasis-endemic region in Brazil. J Mollus Stud 2007 73:45-52.

23. Orrell KS, Jenssen TA: Male mate choice by the lizard Anolis carolinensis: a preference for novel females. Anim Behav 2002, 63: $1091-1102$

24. Petrulis $\mathrm{A}$, Eichenbaum $\mathrm{H}$ : The perirhinal-entorhinal cortex, but not the hippocampus, is critical for expression of individual recognition in the context of the Coolidge effect. Neurosci 2003, I 22:599-607.

25. Koene JM, Ter Maat A: Coolidge effect in pond snails: male motivation in a simultaneous hermaphrodite. BMC Evol Biol 2007, 7:212.

26. Steiger S, Franz R, Eggert A-K, Müller JK: The Coolidge effect, individual recognition and selection for distinctive cuticular signatures in a burying beetle. Proc $R$ Soc Lond B 2008, 275: $1831-1838$.

27. Bateman PW: Mate preference for novel partners in the cricket Gryllus bimaculatus. Ecol Entomol I998, 23:473-475.

28. Sprenger D, Anthes N, Michiels NK: Multiple mating affects offspring size in the opisthobranch Chelidonura sandrana. Mar Biol 2008, I 53:89|-897.

29. Ivy TM, Weddle CB, Sakaluk SK: Females use self-referent cues to avoid mating with previous mates. Proc $R$ Soc Lond B 2005 , 272:2475-2478.

30. Gershman SN, Sakaluk SK: No Coolidge effect in decorated crickets. Ethol 2009, I I 5:774-780.

31. Ziv I, Benni M, Markovich S, Susswein A): Motivational control of sexual behavior in Aplysia fasciata: Sequencing and modulation by sexual deprivation and by addition of partners. Behav Neur Biol 1989, 52:180-193.

32. Zeh JA, Newcomer SD, Zeh DW: Polyandrous females discriminate against previous mates. Proc Natl Acad Sci USA 1998 95: $13732-13736$

33. Archer MS, Elgar MA: Female preference for multiple partners: sperm competition in the hide beetle, Dermestes maculatus (DeGeer). Anim Behav 1999, 58:669-675.

34. Arnaud L, Haubruge $\mathrm{E}$ : Mating behaviour and male mate choice in Tribolium castaneum (Coleoptera, Tenebrionidae). Behav 1999, I 36:67-77.

35. Ödeen A, Moray C: Drosophila melanogaster virgins are more likely to mate with strangers than familiar flies. Naturwiss 2008, 95:253-256.

36. Leonard IL: Sexual conflict and the mating systems of simultaneously hermaphroditic gastropods. Am Malacol Bull I99I, 9:45-58.

37. Koene JM, Ter Maat A: Sex role alternation in the simultaneous hermaphroditic pond snail Lymnaea stagnalis is determined by the availability of seminal fluid. Anim Behav 2005, 69:845-850.

38. Anthes N, Putz A, Michiels NK: Sex role preferences, gender conflict and sperm trading in simultaneous hermaphrodites: a new framework. Anim Behav 2006, 72:1-12.

39. Anthes N, Putz A, Michiels NK: Hermaphrodite sex role preferences: the role of partner body size, mating history and female fitness in the sea slug Chelidonura sandrana. Behav Ecol Sociobiol 2006, 60:359-367.

40. Facon B, Ravigne V, Sauteur L, Goudet J: Effect of mating history on gender preference in the hermaphroditic snail Physa acuta. Anim Behav 2007, 74:|455-|46I.

4I. Sturrock RF: Field studies on the population dynamics of Biomphalaria glabrata, intermediate host of Schistosoma manson on the West Indian Island of St. Lucia. Int J Parasitol I 973, 3: 165.

42. Trigwell JA, Dussart GBJ, Vianey-Liaud M: Pre-copulatory behaviour of the freshwater hermaphrodite snail Biomphalaria glabrata (Say, I 8 I8) (Gastropoda: Pulmonata). J Moll Stud 1997 63:116-120.

43. Vianey-Liaud M: Bias in the production of heterozygous pigmented embryos from successively mated Biomphalaria glabrata (Gastropoda: Planorbidae) albino snails. Malacol Rev 1995, 28:97-106.

44. Vernon JG, Taylor JK: Patterns of sexual roles adopted by the schistosome-vector snail Biomphalaria glabrata (Planorbidae). J Moll Stud 1996, 62:235-24I.
45. Leonard JL, Lukowiak K: Male-female conflict in a simultaneous hermaphrodite resolved by sperm trading. Am Nat 1984, I 24:282-286.

46. Vreys C, Michiels NK: Sperm trading by volume in a hermaphroditic flatworm with mutual penis intromission. Anim Behav 1998, 56:777-785.

47. Anthes N, Putz A, Michiels NK: Gender trading in a hermaphrodite. Curr Biol 2005, I 5:R792-R793.

48. Kitajima EW, Paraense WL: The ultrastructure of the spermatheca of Biomphalaria glabrata (Gastropoda, Pulmonata). J Morphol 1983, I 76:211-220.

49. Rogers $\mathrm{SH}$, Reeder RL: Structure and function of the spermatheca in a snail host of schistosomiasis, Biomphalaria glabrata. J Morphol 1987, I91:295-308.

50. Pimentel D: Life history of Australorbis glabratus, the intermediate snail host of Schistosoma mansoni in Puerto Rico. Ecol 1957, 38:576-580.

5I. Vianey-Liaud M: Growth and fecundity in a black-pigmented and an albino strain of Biomphalaria glabrata (Gastropoda: Pulmonata). Malacol Rev 1989, 22:25-32.

52. Cooper LA, Larson SE, Lewis FA: Male reproductive success of Schistosoma mansoni -infected Biomphalaria glabrata snails. J Parasitol |996, 82:428-43|.

53. Kelley JL, Graves JA, Magurran AE: Familiarity breeds contempt in guppies. Nature 1999, 401:661-662.

54. Townsend CR: Mucus trail following by the snail Biomphalaria glabrata (Say). Anim Behav 1974, 22: I70-177.

55. Wells MJ, Buckley SKL: Snails and trails. Anim Behav 1972 20:345-355.

56. Vianey Liaud M, Nassi H, Lancastre F, Dupouy J: Duration of pairing and use of allosperm in Biomphalaria glabrata (Gastropoda: Planorbidae). Mem Inst Oswaldo Cruz 1989, 84:4 I-45.

57. Webster JP, Hoffman JI, Berdoy M: Parasite infection, host resistance and mate choice: battle of the genders in a simultaneous hermaphrodite. Proc $R$ Soc Lond B 2003, 270: |48|-|485.

58. Lukowiak K, Adatia N, Krygier D, Syed N: Operant conditioning in Lymnaea: Evidence for intermediate- and long-term memory. Learn Mem 2000, 7: I40-I50.

59. Lukowiak K, Sangha S, McComb C, Varshney N, Rosenegger D, Sadamoto $\mathrm{H}$, Scheibenstock $\mathrm{A}$ : Associative learning and memory in Lymnaea stagnalis: how well do they remember? J Exp Biol 2003, 206:2097-2103.

60. Velando A, Eiroa J, Domínguez J: Brainless but not clueless: earthworms boost their ejaculates when they detect fecund non-virgin partners. Proc $R$ Soc Lond B 2008, 275: 1067-1072.

6I. Vernon JG: Low reproductive output of isolated, self-fertilizing snails: Inbreeding depression or absence of social facilitation? Proc $R$ Soc Lond B 1995, 259:131-136.

62. Henry P-Y, Jarne P: Marking hard-shelled gastropods: tag loss, impact on life-history traits, and perspectives in biology. Invert Biol 2007, I 26: I38-I53.

63. Quinn GP, Keough MJ: Experimental Design and Data Analysis for Biologists Cambridge: Cambridge University Press; 2002.

Publish with Bio Med Central and every scientist can read your work free of charge

"BioMed Central will be the most significant development for disseminating the results of biomedical research in our lifetime. "

Sir Paul Nurse, Cancer Research UK

Your research papers will be:

- available free of charge to the entire biomedical community

- peer reviewed and published immediately upon acceptance

- cited in PubMed and archived on PubMed Centra

- yours - you keep the copyright 